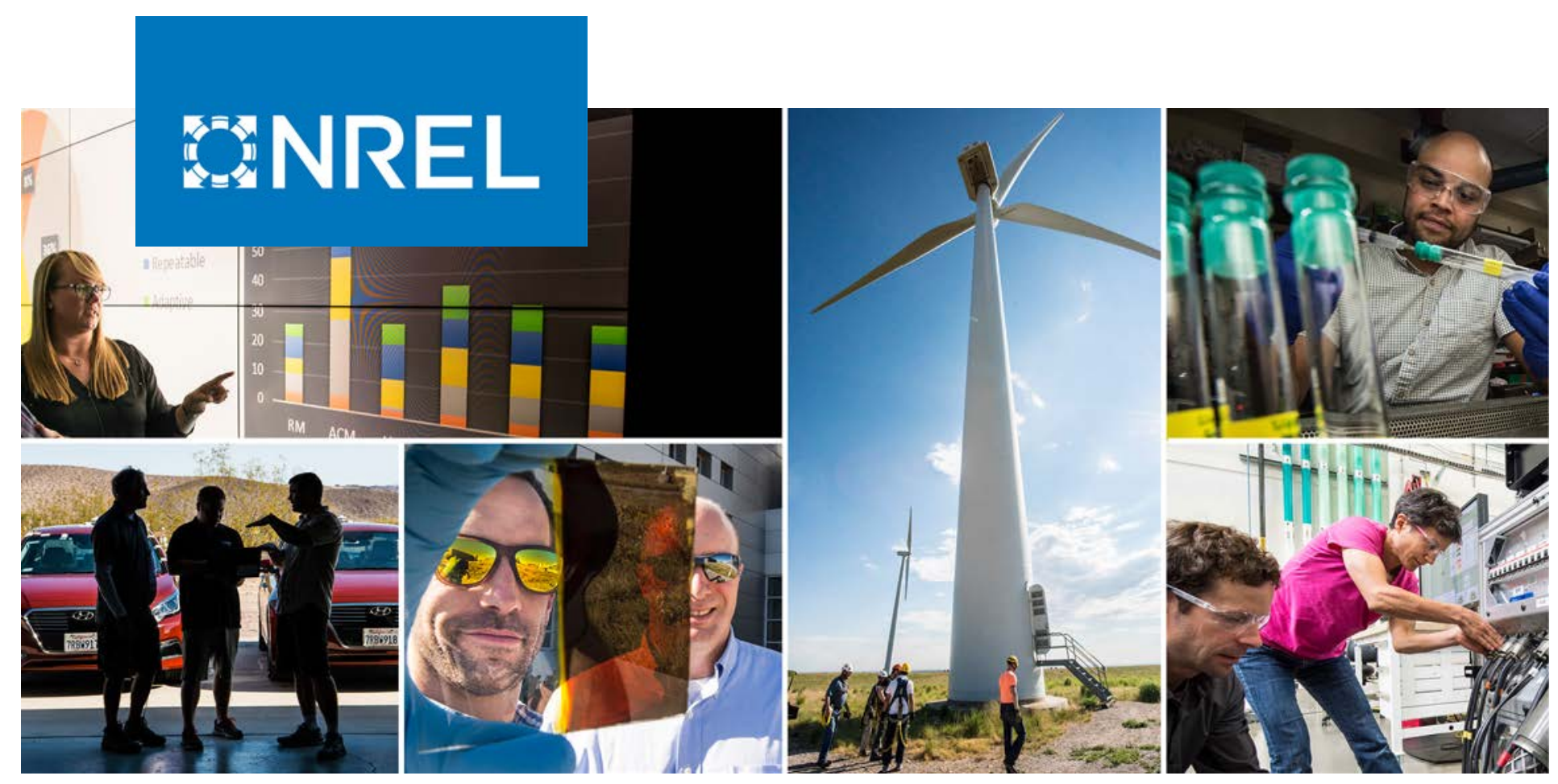

\title{
An Overview of Issues Related to IEEE Std 1547-2018 Requirements Regarding Voltage and Reactive Power Control
}

David Narang, Rasel Mahmud, Michael Ingram, and Andy Hoke

National Renewable Energy Laboratory

NREL is a national laboratory of the U.S. Department of Energy Office of Energy Efficiency \& Renewable Energy

Operated by the Alliance for Sustainable Energy, LLC

This report is available at no cost from the National Renewable Energy Laboratory (NREL) at www.nrel.gov/publications.
Technical Report

NREL/TP-5D00-77156

September 2021 


\section{GNREL}

\section{An Overview of Issues Related to IEEE Std 1547-2018 Requirements Regarding Voltage and Reactive Power Control}

David Narang, Rasel Mahmud, Michael Ingram, and Andy Hoke

National Renewable Energy Laboratory

\section{Suggested Citation}

Narang, David, Rasel Mahmud, Michael Ingram, and Andy Hoke. 2021. An Overview of Issues Related to IEEE Std 1547-2018 Requirements Regarding Voltage and Reactive Power Control. Golden, CO: National Renewable Energy Laboratory. NREL/TP-5D0077156. https://www.nrel.gov/docs/fy21osti/77156.pdf.

NREL is a national laboratory of the U.S. Department of Energy Office of Energy Efficiency \& Renewable Energy Operated by the Alliance for Sustainable Energy, LLC

This report is available at no cost from the National Renewable Energy Laboratory (NREL) at www.nrel.gov/publications.

Contract No. DE-AC36-08GO28308
Technical Report

NREL/TP-5D00-77156

September 2021

National Renewable Energy Laboratory 15013 Denver West Parkway Golden, CO 80401 303-275-3000 • www.nrel.gov 


\section{NOTICE}

This work was authored by the National Renewable Energy Laboratory, operated by Alliance for Sustainable Energy, LLC, for the U.S. Department of Energy (DOE) under Contract No. DE-AC36-08GO28308. Funding provided by U.S. Department of Energy Office of Energy Efficiency and Renewable Energy Solar Energy Technologies Office. The views expressed herein do not necessarily represent the views of the DOE or the U.S. Government.

This report is available at no cost from the National Renewable Energy Laboratory (NREL) at www.nrel.gov/publications.

U.S. Department of Energy (DOE) reports produced after 1991 and a growing number of pre-1991 documents are available free via www.OSTI.gov.

Cover Photos by Dennis Schroeder: (clockwise, left to right) NREL 51934, NREL 45897, NREL 42160, NREL 45891, NREL 48097, NREL 46526.

NREL prints on paper that contains recycled content. 


\section{Preface}

The revised Institute of Electrical and Electronics Engineers (IEEE) 1547 Standard for Interconnection and Interoperability of Distributed Energy Resources with Associated Electric Power Systems Interfaces (IEEE Std 1547-2018) was published in April 2018. This standard is one of the foundational documents in the United States needed for integrating distributed energy resources (DERs), including solar energy systems, with the electric distribution grid.

The revised standard contains 11 chapters (clauses) and 8 annexes that comprise 136 pages. The revision is significantly different from the 2003 version, and it contains new concepts and new technical requirements. Each clause specifies information or requirements that apply to certain aspects important to the interconnection of DERs to the electric power system. Implementing the requirements necessitates a careful study of the underlying technical concept and requires the appropriate information required to calculate relevant settings and configurations.

Various stakeholders have different roles in implementing the standard, and portions of the standard are directed toward a specific audience who must possess specialized information and technical training to use and apply the requirements.

This document aims to (1) summarize a specific portion of the standard as concisely as possible and (2) provide the reader with introductory knowledge and information to support the utilization of the requirements.

Note that the narrative on the implementation and configurability of requirements reflects the authors' interpretations, which in some instances might differ from one person to another, especially at this early stage of implementation. Therefore, this work is intended to supplement the existing and growing body of knowledge across the U.S. electric sector on the use and application of this important standard. 


\section{Acknowledgments}

This material is based upon work supported by the U.S. Department of Energy Office of Energy Efficiency and Renewable Energy under the Solar Energy Technologies Office Award Number 34808.

The authors thank John Berdner, Robert Harris, Jason Allnutt, Jens C. Boemer, Michele Boyd, Brian Lydic, Joe Palladino, John Shenot, Ravi Subramaniam, and Kiera Zitelman for their review and valuable comments.

The authors are also grateful to the U.S. Department of Energy Office of Energy Efficiency and Renewable Energy Solar Energy Technologies Office Strategic Analysis and Institutional Support Program Manager Michele Boyd and to technical monitors Jeremiah Miller and Robert Reedy. 


\section{List of Acronyms}

AEPSO $^{1}$

AGIR

ANSI

DER

DERO $^{2}$

EPS

IEEE

NEMA

NREL

p.f.

p.u.

PV

SCE

$\operatorname{var}^{3}$ area electric power system operator

Authority Governing Interconnection Requirements

American National Standards Institute

distributed energy resource

distributed energy resource operator

electric power system

Institute of Electrical and Electronics Engineers

National Electrical Manufacturers Association

National Renewable Energy Laboratory

power factor

per unit

photovoltaic

Southern California Edison

volt-ampere reactive

${ }^{1}$ Note that the standard uses the term area EPS operator, not the acronym AEPSO, which is used in this document.

${ }^{2}$ Note that the standard uses the term DER operator, not the acronym DERO, which is used in this document.

${ }^{3}$ This document uses the IEEE Std 270-2006 convention for the name and symbol var for reactive power. (For reference, see IEEE Std 270-2006 definitions 3.251 for reactive power and 3.327 for var.) 


\section{Table of Contents}

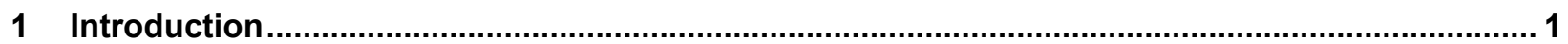

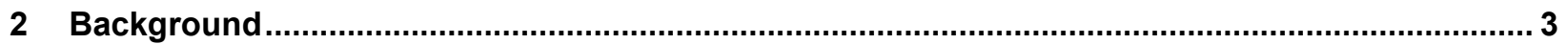

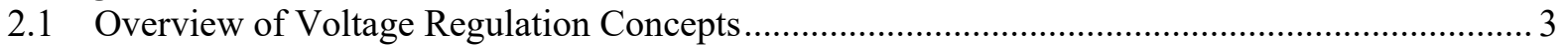

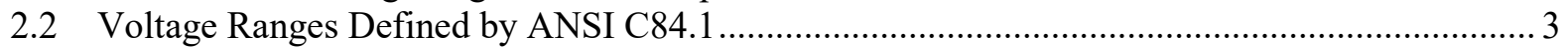

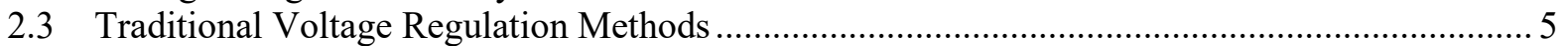

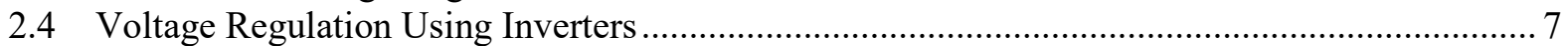

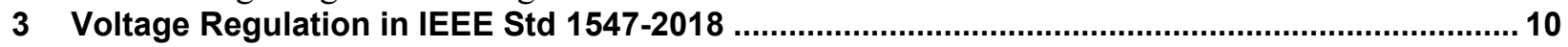

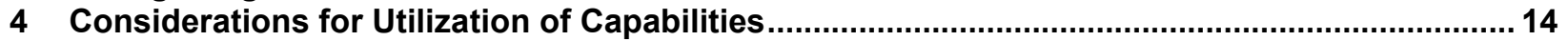

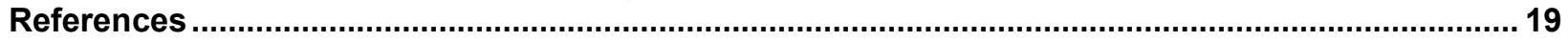

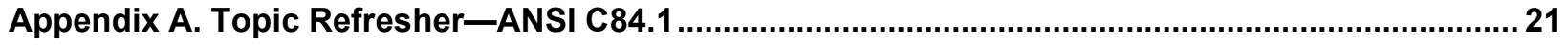

Appendix B. Advanced Voltage Regulation-A Hawaii Case Study .................................................. 23

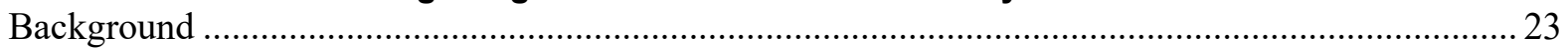

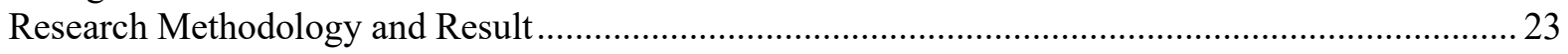

Implementation Experience of Voltage Regulation Functions....................................................... 24 


\section{List of Figures}

Figure 1. Example voltage profile along distribution feeder on a $120-\mathrm{V}$ basis ........................................ 5

Figure 2. Illustrative example of DER-induced voltage rise on a distribution feeder................................ 6

Figure 3. Example voltage profile at peak load with regulation by shunt capacitor ................................... 7

Figure 4. Example voltage profile at peak load with regulation by voltage regulator ................................ 7

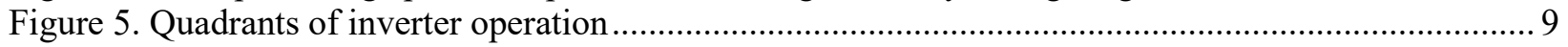

Figure 6. Example of IEEE Std 1547-2018 Category B default characteristic for voltage-reactive power

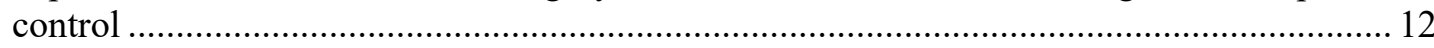

Figure 7. Example of IEEE Std 1547-2018 Category B default characteristic for active power-reactive

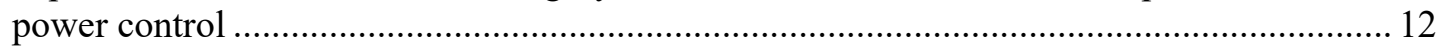

Figure 8. Example of default characteristic for voltage-active power control......................................... 13

Figure 9. Results of application of voltage regulation inverters on the hosting capacity of three test feeders

\section{List of Tables}

Table 1. ANSI Voltage Ranges and Limits for Residential Single-Phase Systems .................................... 4

Table 2. IEEE Std 1547-2018 Active Voltage Regulation Requirements .............................................. 11

Table A-1. ANSI Voltage Ranges and Limits for Residential Single-Phase Systems.............................. 22 


\section{Introduction}

This document aims to provide supplementary information to help stakeholders ${ }^{4}$ to apply the requirements specified in Clause 5 of the revised Institute of Electrical and Electronics Engineers (IEEE) 1547 Standard for Interconnection and Interoperability of Distributed Energy Resources with Associated Electric Power Systems Interfaces (IEEE Std 1547-2018).

Clause 5 contains requirements for reactive power and voltage/power control capabilities of distributed energy resources (DERs). Four subclauses describe the overall capabilities and detailed requirements for specifics modes of operation. Table 6 in the standard lists the types of voltage regulation required depending on the DER normal operating performance category A or B. Informative Annex B presents discussion and considerations for performance category assignment. Annex H shows examples of control mode plots.

The clause is directed primarily to electric utilities (the area electric power system operator, AEPSO), DER operators, DER device manufacturers, ${ }^{5}$ testing agencies ${ }^{6}$ and laboratories, and commissioning agencies. For determination of performance categories, the Authority Governing Interconnection Requirements (AGIR) ${ }^{7}$ might choose to provide guidance to the AEPSO.

It is assumed that the reader possesses the appropriate training and experience necessary to understand and apply the stated requirements. This could include foundational electrical engineering knowledge, knowledge of area electric power system (EPS) device settings, parameters and operational practices, and knowledge of general and specific DER capabilities relevant to the subject.

This document aims to provide a high-level summary of the context and background concepts for requirements related to voltage regulation. This document is intended as a supplement to material already published or in development. ${ }^{8}$ This is not intended as an exhaustive resource on technical

\footnotetext{
${ }^{4}$ Note that although DER manufacturers are a primary stakeholder, their concerns are equipment design and manufacturing. This document is intended to provide an overall summary for stakeholders involved in the application of the standard.

${ }^{5}$ Solar and other DER device manufacturers are inherently interested in the performance requirements in this standard; however, this document focuses on the application of the standard rather than the manufacturing process of the DER device.

${ }^{6}$ The term testing agency includes entities such as nationally recognized testing laboratories (NRTLs).

${ }^{7}$ IEEE Std 1547-2018 defines the Authority Governing Interconnection Requirements (AGIR) as "cognizant and responsible entity that defines, codifies, communicates, administers, and enforces the policies and procedures for allowing electrical interconnection of DER to the Area EPS. This may be a regulatory agency, public utility commission, municipality, cooperative board of directors, etc. The degree of AGIR involvement will vary in scope of application and level of enforcement across jurisdictional boundaries. This authority may be delegated by the cognizant and responsible entity to the Area EPS operator or bulk power system operator. NOTE-Decisions made by an authority governing interconnection requirements should consider various stakeholder interests, including but not limited to Load Customers, Area EPS operators, DER operators, and bulk power system operator" (IEEE 15472018).

${ }^{8}$ For example, see the expected revision to IEEE Std 1547.2, Application Guide for IEEE Std 1547.
} 
implementation. Rather, topics are presented at a level appropriate to serve individuals who require an introduction or technical refresher to the material. 


\section{Background}

\subsection{Overview of Voltage Regulation Concepts}

Maintaining voltage within appropriate levels is one of the most important responsibilities for distribution utilities. The "appropriate" voltage level is defined by a standard from the American National Standards Institute, ANSI C84.1, and it is typically referenced in utility electric service requirements and interconnection rules. Utilities employ a variety of devices to maintain the voltage within these levels, including capacitors and voltage regulators. A high-level overview of these concepts is provided in the following sections.

\subsection{Voltage Ranges Defined by ANSI C84.1}

ANSI C84.1 specifies voltage ratings and requirements for electricity systems in the United States. The standard dictates the voltage ranges at which an AEPSO must maintain typical distribution systems, and it dictates the operating range of voltages that must be designed into equipment connecting to the distribution system, including all end-user loads and DERs. Key terms defined in ANSI C $84.1^{9}$ are used extensively in utility practice and are referenced by IEEE Std 1547-2018.

Under normal operating conditions, the AEPSO must maintain the service voltage within the minimum and maximum given for Range A. Voltage may only stray outside Range A infrequently, and then only up to limits within Range B.

ANSI C84.1 does not specify requirements on how often the service voltage may cross into Range B or define an acceptable duration for the service voltage to remain within this range. An area EPS experiences occasional voltage excursions outside Range B, especially during transient events; for this reason, DERs are required by IEEE Std 1547-2018 to have verifiable performance outside Range B. ANSI C84.1 does not apply to momentary voltage excursions (i.e., sags or swells). Typically, excursions within this momentary time frame are considered a power quality issue and are less than 1 minute. ${ }^{10}$ Note that promptly restoring the service voltage to Range A is in the best interest of all - the AEPSO and the customer - to ensure the satisfactory operation of EPS protective devices.

Table 1 lists the base voltage ranges, limits, and corresponding per-unit (p.u.) values for residential single-phase systems specified in ANSI C84.1.

\footnotetext{
${ }^{9}$ For a short summary of ANSI C84.1, see the topic refresher on ANSI C84.1 (Appendix A).

${ }^{10}$ See IEEE Std 1159-2019, “IEEE Recommended Practice for Monitoring Electric Power Quality” for more information on general classification of power quality phenomena.
} 
Table 1. ANSI Voltage Ranges and Limits for Residential Single-Phase Systems

\begin{tabular}{|l|c|c|c|c|c|}
\hline & $\begin{array}{c}\text { Nominal } \\
\text { System Voltage }\end{array}$ & \multicolumn{2}{|c|}{ Service Voltage } & \multicolumn{2}{c|}{ Utilization Voltage } \\
\hline & $\mathrm{V}$, (p.u.) & $\begin{array}{c}\text { Minimum } \\
\mathrm{V},(\text { p.u. })\end{array}$ & $\begin{array}{c}\text { Maximum } \\
\mathrm{V},(\mathrm{p} . \mathrm{u} .)\end{array}$ & $\begin{array}{c}\text { Minimum } \\
\mathrm{V},(\mathrm{p} . \mathrm{u} .)\end{array}$ & $\begin{array}{c}\text { Maximum } \\
\mathrm{V}, \text { (p.u. })\end{array}$ \\
\hline $\begin{array}{l}\text { Voltage } \\
\text { Range A }\end{array}$ & $120,(1.00)$ & $114,(0.95)$ & $126,(1.05)$ & $108,(0.90)$ & $125,(\approx 1.04)$ \\
\hline $\begin{array}{l}\text { Voltage } \\
\text { Range B }\end{array}$ & $120,(1.00)$ & $110,(\approx 0.92)$ & $127,(\approx 1.06)$ & $104,(\approx 0.87)$ & $127,(\approx 1.06)$ \\
\hline
\end{tabular}

See ANSI C84.1-2016 for a more complete discussion of requirements.

Typically, electric distribution utilities reference ANSI C84.1 as the basis of their electric service requirements and choose values for service and utilization voltage to be within the limits set in ANSI C84.1. For example, Southern California Edison states that for a nominal 120-V residential service, the minimum and maximum service voltages shall be $114 \mathrm{~V}$ and $120 \mathrm{~V}$ (126 $\mathrm{V}$ max on agricultural and industrial distribution circuits), respectively (SCE 2021).

In distribution circuits that supply more power to loads than is produced by DERs, and in the absence of voltage regulation devices, voltage typically decreases as the distance from the substation increases according to the length of the circuit, the characteristics of electrical distribution wires, and the amount of connected load. DERs can cause the voltage not to decrease as much as planned or even to increase along the length of the feeder. Despite these conditions, utilities must maintain the voltage within the limits discussed. These concepts are illustrated in Figure 1, which also shows the ANSI voltage limits for service and utilization voltage ranges A and $\mathrm{B}$ for a nominal $120-\mathrm{V}$ system. Note that the distribution feeder, the distribution transformer, the secondary service wiring, and the customer wiring typically contribute to some loss of voltage, and therefore the per-unit voltage at the electric outlet will be some value less than the voltage at the distribution primary. One source notes that a voltage drop of $4 \mathrm{~V}$ between the point of delivery and the point of utilization is acceptable based on a 120-V base (Gonen 2008). A value of $3 \mathrm{~V}$ is given for the voltage drop along the primary from the substation to the end of the feeder (Palmintier et al. 2016). 


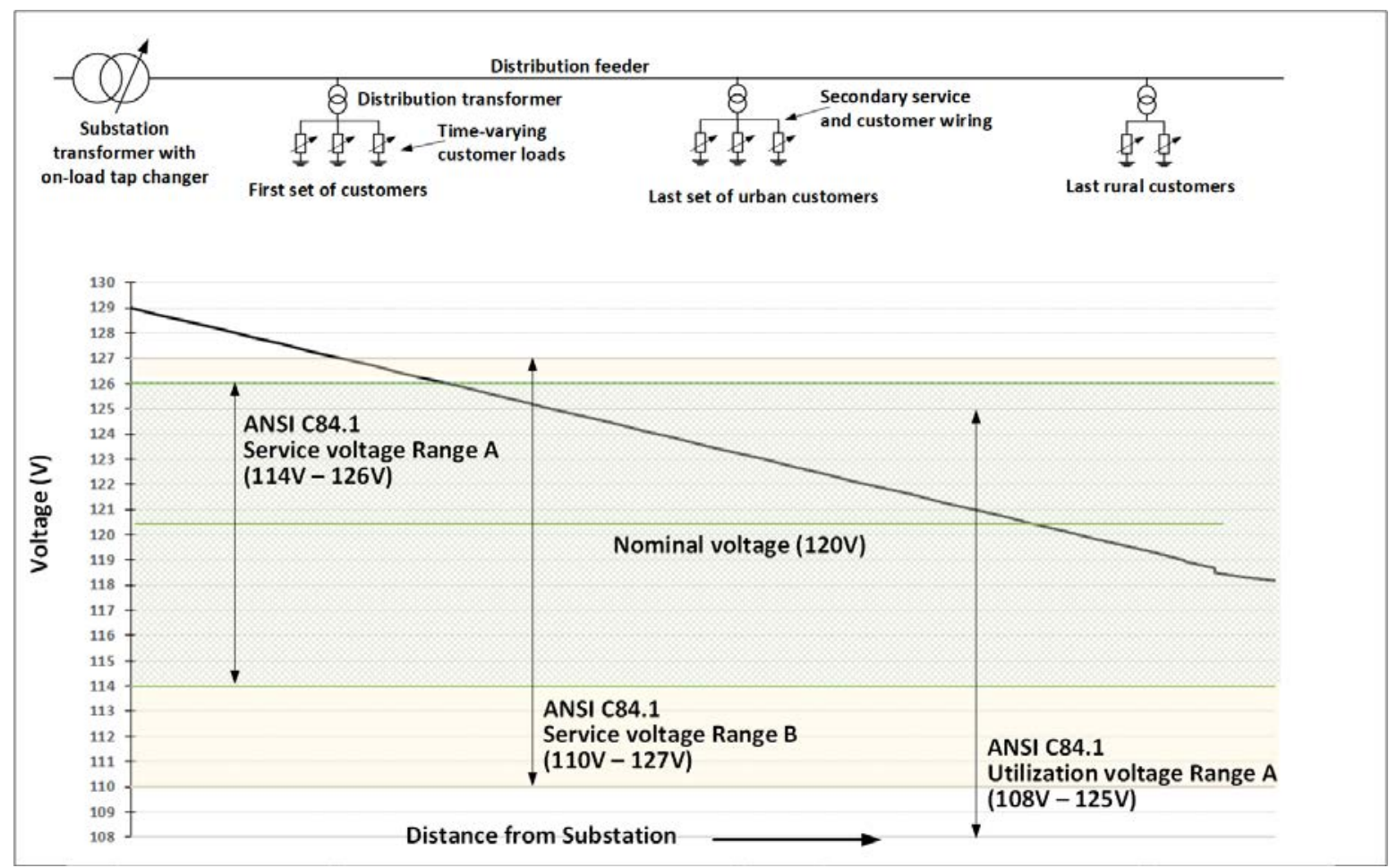

Source: Adapted from Gonen (2008) and McGranaghan et al. (2008)

Figure 1. Example voltage profile along distribution feeder on a $120-\mathrm{V}$ basis

\subsection{Traditional Voltage Regulation Methods}

Based on experience, distribution voltage has been traditionally known to stray outside limits for a variety of reasons, including daily or seasonal changes in loading conditions, from low load to high load, and load density along the feeder; load balancing operations; unbalanced loads and feeders; and new loads. The advent of DERs has also added a potential new source of voltage excursions - namely, the DER itself as a result of the power injection (in reverse of normal loads) at the DER location. ${ }^{11}$ An illustrative example of DER-induced voltage rise on a distribution feeder is shown in Figure 2. Note that the figure illustrates DERs operating at unity power factor without active voltage regulation ${ }^{12}$ (i.e., IEEE Std 1547-2003 settings).

\footnotetext{
${ }^{11}$ See McGranaghan et al. (2008) for an explanation and equation describing this effect.

${ }^{12}$ For a short background on power factor and the relationships between active and reactive power, see the topic refresher on the power triangle (https://www.nrel.gov/docs/fy21osti/78472.pdf).
} 


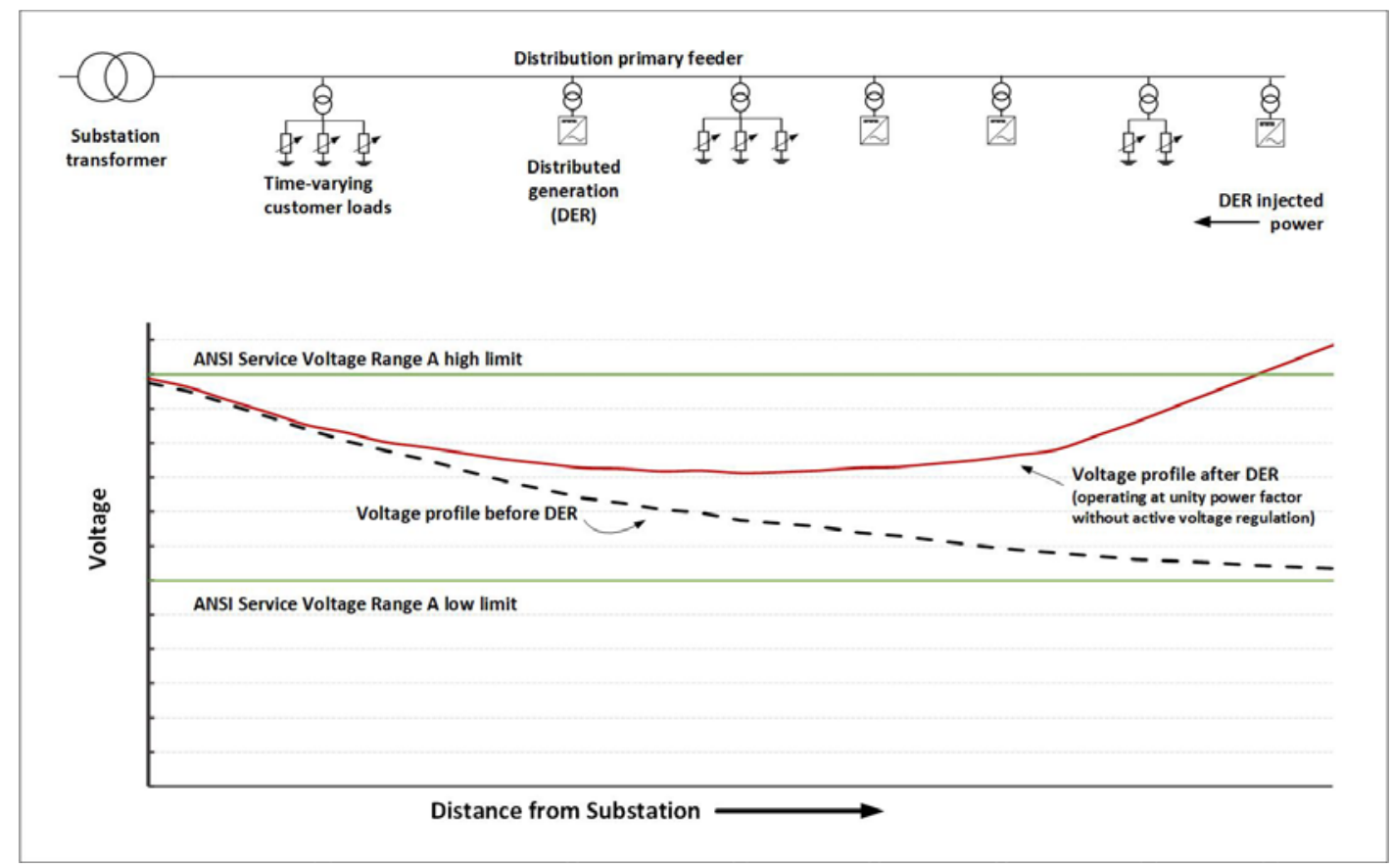

Source: Adapted from McGranaghan et al. (2008)

Figure 2. Illustrative example of DER-induced voltage rise on a distribution feeder

Utilities have traditionally employed a variety of typical ${ }^{13}$ distribution equipment to remedy voltage regulation issues. A partial list is given by Gonen (2008):

1. Using generator voltage regulators

2. Using voltage-regulating equipment at the distribution substation

3. Using capacitors at the distribution substation

4. Rebalancing load on the feeder primary

5. Increasing feeder conductor capacity

6. Changing feeder sections from single phase to multiphase

7. Transferring load to different feeders

8. Installing new substation and primary feeder

9. Increasing primary voltage level

10. Using voltage regulators on the feeder primary

11. Using shunt capacitors on the feeder primary

The effects of voltage regulation by a shunt capacitor and a voltage regulator are shown in Figure 3 and Figure 4.

\footnotetext{
${ }^{13}$ Atypical equipment that can also be used include static var compensators
} 


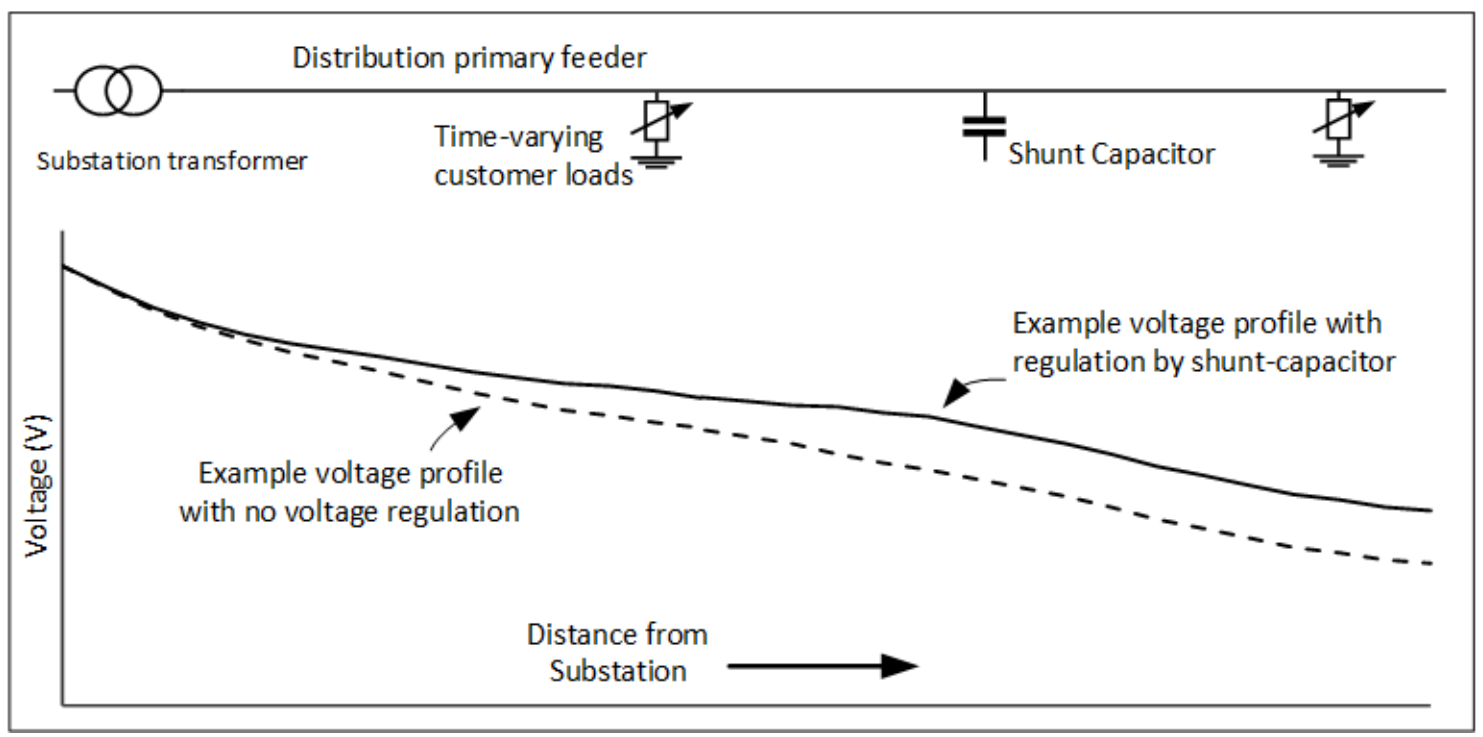

Source: Adapted from Beaty and Fink (2013, 18.29)

Figure 3. Example voltage profile at peak load with regulation by shunt capacitor

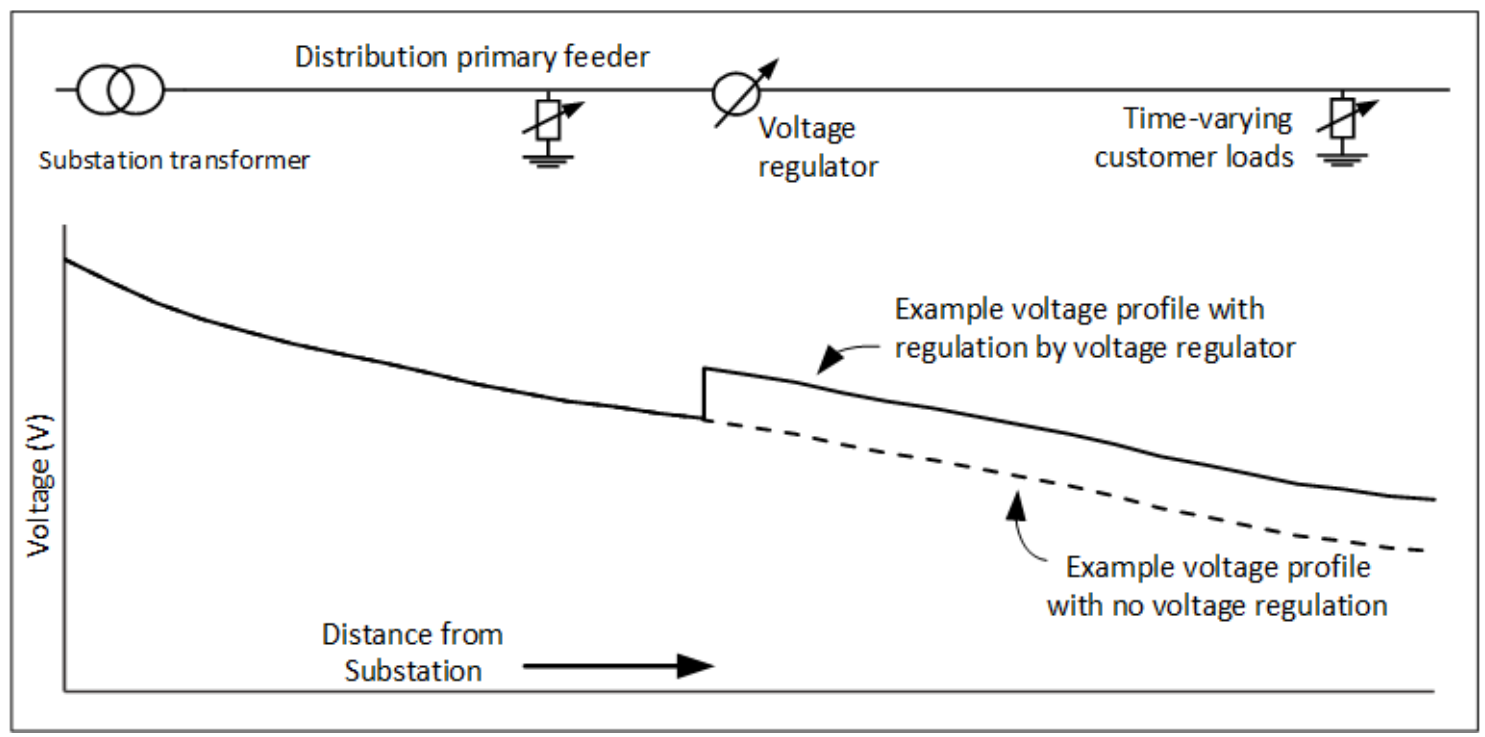

Source: Adapted from Beaty and Fink (2013, 18.29)

Figure 4. Example voltage profile at peak load with regulation by voltage regulator

In reviewing the list of traditional methods for voltage regulation, note that most solutions have been applied at either the substation or on the feeder primary. In recent years, additional methods for voltage regulation have been developed. These include the use of electronic volt ampere reactive (var) compensators, voltage-regulating distribution transformers, and DERs, specifically inverters.

\subsection{Voltage Regulation Using Inverters}

Modern photovoltaic (PV) and battery energy storage inverters also have voltage regulation capability, and they can play an important role in helping to regulate distribution voltages by 
providing both active and reactive power support. Simply by modulating the phase angle (essentially the timing) of the inverter's output current with respect to voltage, the inverter can source or sink reactive power, in effect acting like a capacitor or inductor, and hence decreasing or increasing the voltage change in the distribution conductors. An inverter can also modulate its active power magnitude, which also changes the voltage drop (or rise) on the distribution conductors.

The voltage regulation capabilities of modern inverters can help manage undervoltage and overvoltage problems, which are commonly stated as a concern on distribution circuits with high penetrations of DERs. Inverters with a lagging power factor setting (i.e., absorbing reactive power) can help mitigate voltage rise; similarly, inverters with a leading power factor setting (i.e., injecting reactive power) can help mitigate voltage drop. Both settings can potentially increase circuit hosting capacity.

Modern electronic controls allow inverters to operate in multiple quadrants, as shown in Figure 5. Depending on where the inverter operates, its effect on the feeder voltage profile varies. This allows it to participate in voltage regulation. 


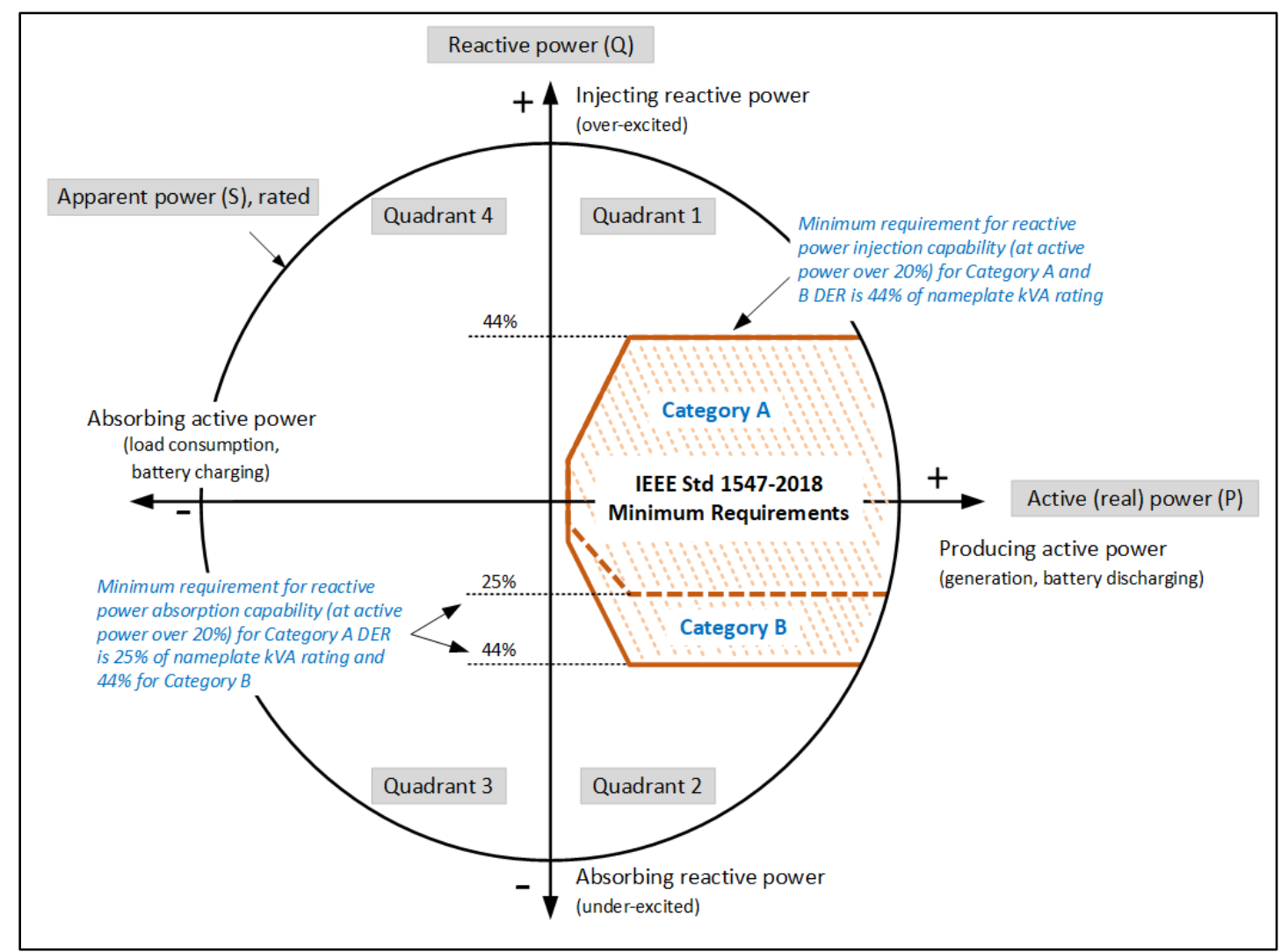

Source: Adapted from McGranaghan et al. (2008) and IEEE (2018)

Figure 5. Quadrants of inverter operation ${ }^{14}$

${ }^{14}$ Note that quadrants 3 and 4 are achievable only with inverters connected to energy storage systems. 


\section{Voltage Regulation in IEEE Std 1547-2018}

Applying DERs to regulate voltage was initially prohibited by IEEE Std 1547-2003. In the 2015 amendment (IEEE Std 1547a-2014), voltage regulation was allowed, and it later became required in California and Hawaii.

In IEEE Std 1547-2018, voltage regulation capability ${ }^{15}$ is mandatory for all DERs; that is, all IEEE Std 1547-2018-compliant DERs shall have the capability to inject and absorb reactive power (overexcited and underexcited), within certain limitations. ${ }^{16}$ It was recognized, however, that various DER technologies will inherently have varying levels of reactive power capability; therefore, the term normal operating performance category (Category A and B) was developed to differentiate between DERs with more or less capability. Category A was designed to accommodate DERs with reduced active and reactive power control capabilities, including noninverter-based DERs; most inverter-based DERs (i.e., PV and BESS) are expected to have the increased capabilities associated with Category B. Figure 6 shows the IEEE Std 1547-2018 minimum requirements for reactive power injection and absorption for both DER categories.

Clause 5 in IEEE Std 1547-2018 contains requirements for reactive power and voltage/power control capabilities of DERs. Four subclauses describe the overall capabilities and detailed requirements for specific modes of operation. Table 6 in the standard lists the types of voltage regulation required depending on the DER normal operating performance category A or B. Annex H shows examples of active and reactive control characteristics (IEEE 1547-2018).

Voltage regulation capability requirements for Category A and Category B are shown in Table 2.

\footnotetext{
${ }^{15}$ Note that in IEEE Std 1547-2018, DER voltage regulation capability is mandatory. Utilization of this capability is up to specific jurisdictions; however, numerous studies and pilots have concluded that utilization of this capability under various conditions might be beneficial. For examples of this research, see the additional educational resources at https://www.nrel.gov/grid/ieee-standard-1547/.

${ }^{16}$ Clause 5 in the standard specifies the reactive power capability and voltage/power control requirements.
} 
Table 2. IEEE Std 1547-2018 Active Voltage Regulation Requirements

\begin{tabular}{|c|c|c|c|c|c|}
\hline $\begin{array}{c}\text { Normal } \\
\text { Operating } \\
\text { Performance } \\
\text { Category }\end{array}$ & $\begin{array}{c}\text { Constant } \\
\text { Power } \\
\text { Factor }\end{array}$ & $\begin{array}{c}\text { Constant } \\
\text { Reactive } \\
\text { Power }\end{array}$ & $\begin{array}{c}\text { Voltage- } \\
\text { Reactive } \\
\text { Power }\end{array}$ & $\begin{array}{c}\text { Active Power- } \\
\text { Reactive } \\
\text { Power }^{\mathbf{b}}\end{array}$ & $\begin{array}{c}\text { Voltage- } \\
\begin{array}{c}\text { Active } \\
\text { Power }\end{array}\end{array}$ \\
\hline Category A & Required & Required & Required & Not required & Not required \\
\hline Category B & Required & Required & Required & Required & Required \\
\hline
\end{tabular}

a Also known as volt-var

${ }^{b}$ Also known as watt-var

${ }^{\mathrm{c}}$ Also known as volt-watt

Category A DERs meet the minimum performance capabilities needed for area EPS voltage regulation and should be reasonably attainable by all state-of-the-art DER technologies.

Category B DERs meet all requirements in Category A and have additional capabilities for supporting high DER penetration. Category B is attainable by most smart inverters.

Both Category A and Category B DERs must be capable of operating in three voltage regulation modes: (1) constant power factor mode, (2) constant reactive power mode, and (3) voltagereactive power ("volt-var") mode. Category B DERs must have additional capability for two other modes: (4) active power-reactive power mode and (5) voltage-active power ("volt-watt") mode.

In any mode that requires reactive power control, the DER must source or sink the designated reactive power even if it must sacrifice active power output to do so. This is referred to as "reactive power priority." ${ }^{17}$ For example, when in volt-var mode, the DER must follow the voltvar curve even if it needs to reduce active power. Because of this, the use of voltage regulation capabilities might impact the energy production of DERs; however, recent detailed studies by the National Renewable Energy Laboratory (NREL) have found this impact to be minimal for most DERs (Giraldez et al. 2017).

In constant power factor mode, the DER operates at a constant power factor, modulating reactive power to hold the ratio of active and reactive power constant as active power changes.

In constant reactive power mode, the DER maintains a constant reactive power output regardless of active power output.

In voltage-reactive power mode - also known as volt-var mode - the DER actively controls its reactive power output as a function of voltage, which typically acts to push local voltage back toward nominal. This mode is designed so that the DER supplies or absorbs reactive power only when needed to mitigate voltage deviations. An example of the characteristic curve for this

\footnotetext{
${ }^{17}$ See https://www.cpuc.ca.gov/WorkArea/DownloadAsset.aspx?id=6442454143 for a recommendation on this mode from California Public Utilities Commission staff to California Public Utilities Commission.
} 
capability is shown in Figure 6. Details for this mode are in Clause 5.3.3 and Table 8 in the standard.

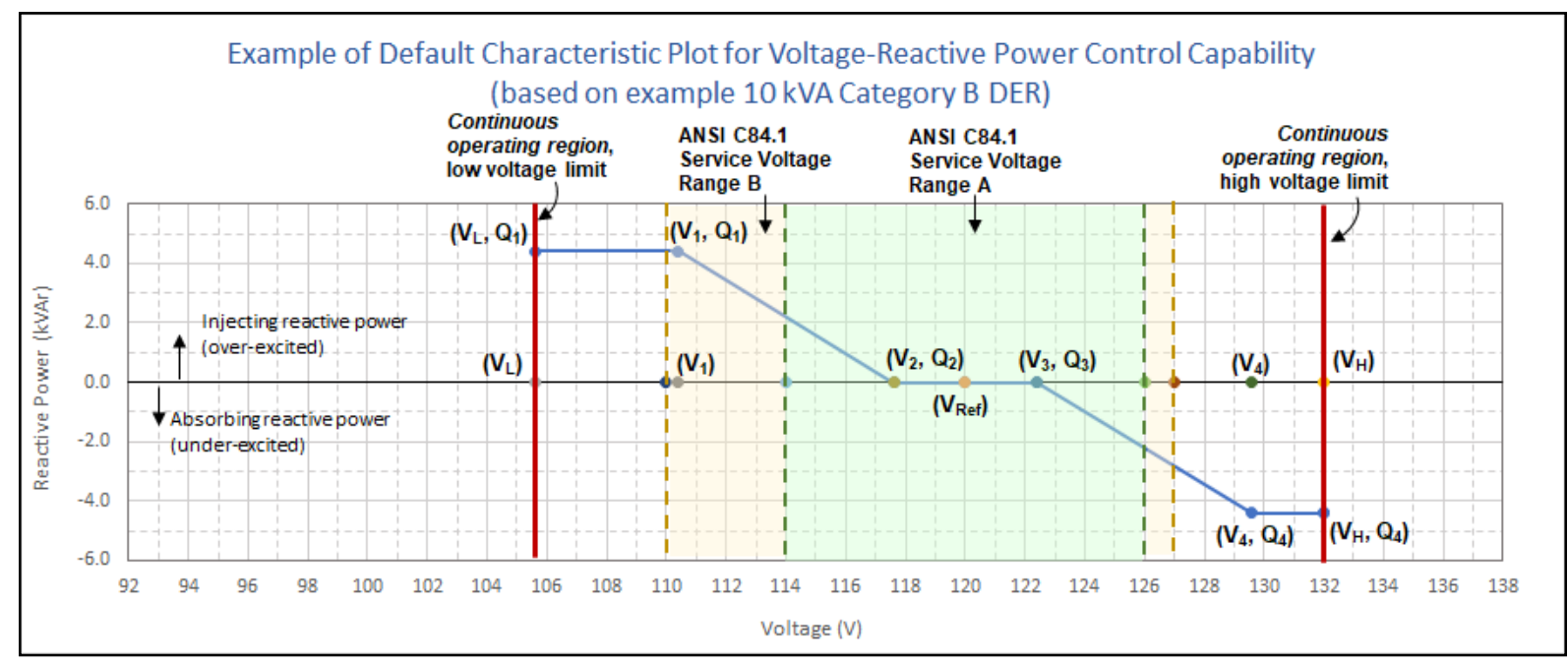

Figure 6. Example of IEEE Std 1547-2018 Category B default characteristic for voltage-reactive power control

In active power-reactive power mode - also known as watt-var mode - the DER actively controls the reactive power output as a function of the active power output. An example of the characteristic curve for this capability is shown in Figure 7. Details are provided in Clause 5.3.4 and Table 9 in the standard, with an example in Appendix H, Figure H-5. This mode has not yet seen significant use in the field, but it could be used more often as DER amounts increase.

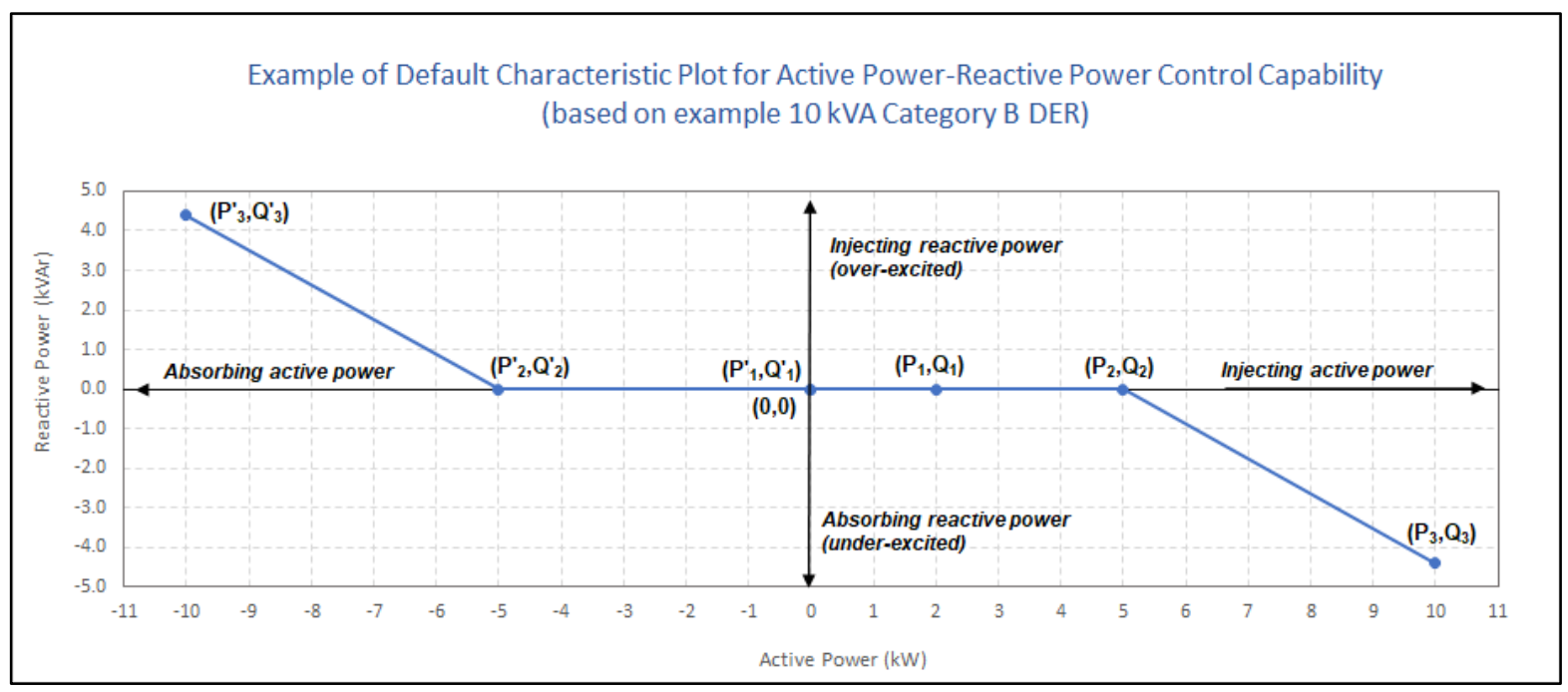

Figure 7. Example of IEEE Std 1547-2018 Category B default characteristic for active powerreactive power control

In voltage-active power mode - also known as volt-watt mode - the DER actively limits its maximum active power as a function of the voltage. Unlike the reactive power control modes, where the DER reactive power is required to be on the specified curve, in volt-watt mode, the active power is required to be on or below the specified curve. This mode is required to be 
enabled simultaneously with other modes, such as volt-var mode. This mode can be used to reduce the prevalence of very high voltages.

For DERs able to absorb active power, such as energy storage, the active power can go to less than zero. Examples of the characteristic curve for this capability are shown in Figure 8 for DERs with and without active power absorption capability. Details are given in IEEE Std 15472018 Clause 5.4.2 and Table 10, with an example given in Appendix H, Figure H-6.

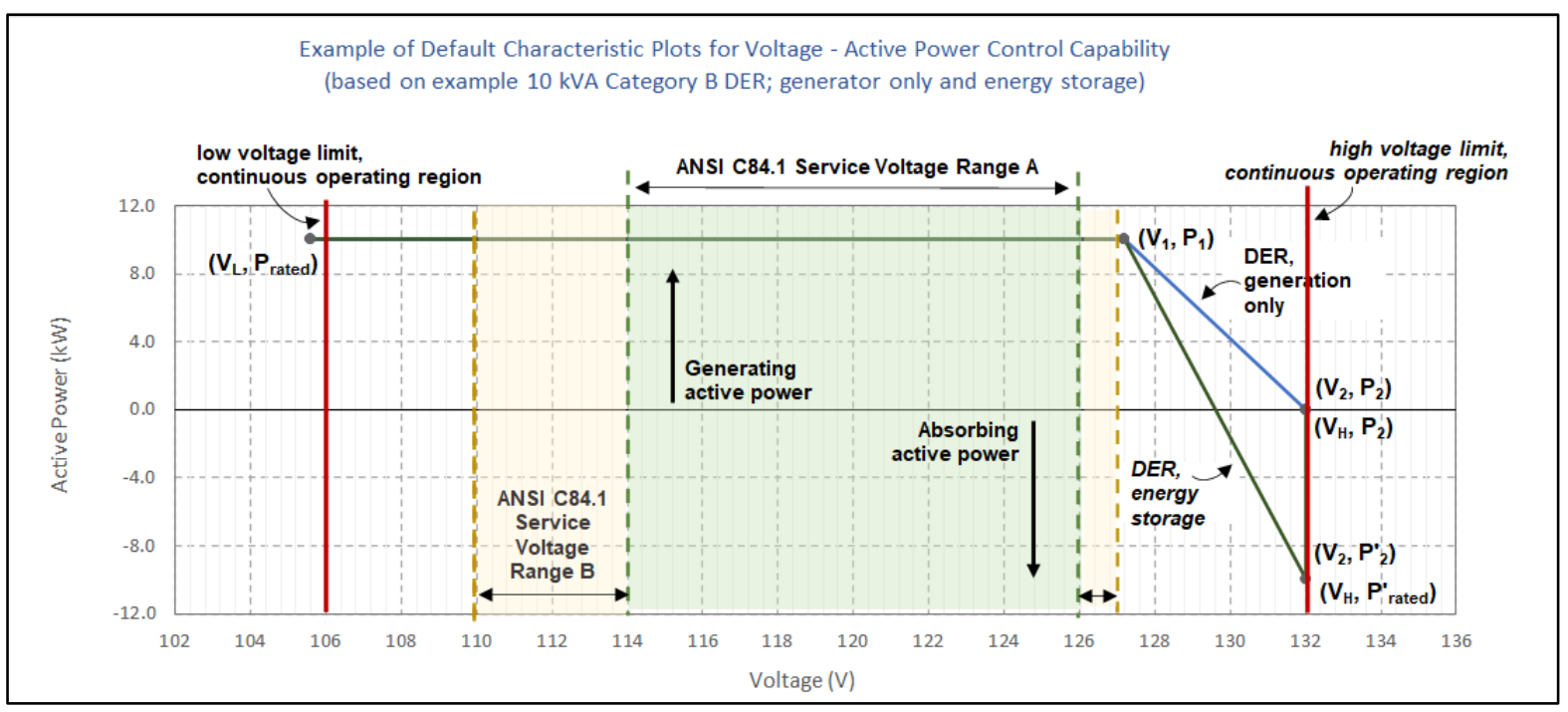

Figure 8. Example of default characteristic for voltage-active power control 


\section{Considerations for Utilization of Capabilities}

As the amount of distributed energy, especially inverter-based PV systems, has increased during the past decade, so too has grown the interest in using advanced inverter functions to increase the DER hosting capacity on distribution feeders. Numerous studies have shown that voltage regulation using advanced inverters is possible, and field demonstrations have shown that advanced inverter capabilities can be deployed in the field and can achieve the results predicted by the studies. As might be expected, however, many factors affect how well these voltage regulation techniques work in a specific location. The most important of these factors are line reactance and resistance. Others are variations in feeder topology, configuration, and loading.

A 2016 report by NREL, Sandia National Laboratories, and the Massachusetts Institute of Technology noted that for a set of 18 utility distribution feeders, voltage regulation using advanced inverters could help increase the feeder hosting capacity. This report also noted the significant variations resulting from feeder configuration (Palmintier et al. 2016).

Figure 9 shows simulation results from the Palmintier et al. (2016) report of applying inverter voltage regulation on the hosting capacity for three of the feeders studied. The base case, shown as the blue bar, indicates inverters operating at constant power factor-unity power factor, which is the default mode in IEEE Std 1547-2018. The green bar shows what would happen if all PV inverters were operating at a power factor of 0.98 absorbing. As shown in the figure, this results in a higher hosting capacity. The yellow bar indicates the result of using the voltage-reactive power control mode using less aggressive settings. As shown in the figure, this mode does not provide a consistent increase in hosting capacity across three feeder types; however, for Feeder 2 , it is dramatically better than the other modes. For feeders 1 and 3, the voltage-reactive power mode provides less hosting capacity increase than adjusting the power factor from unity to 0.98 absorbing. 


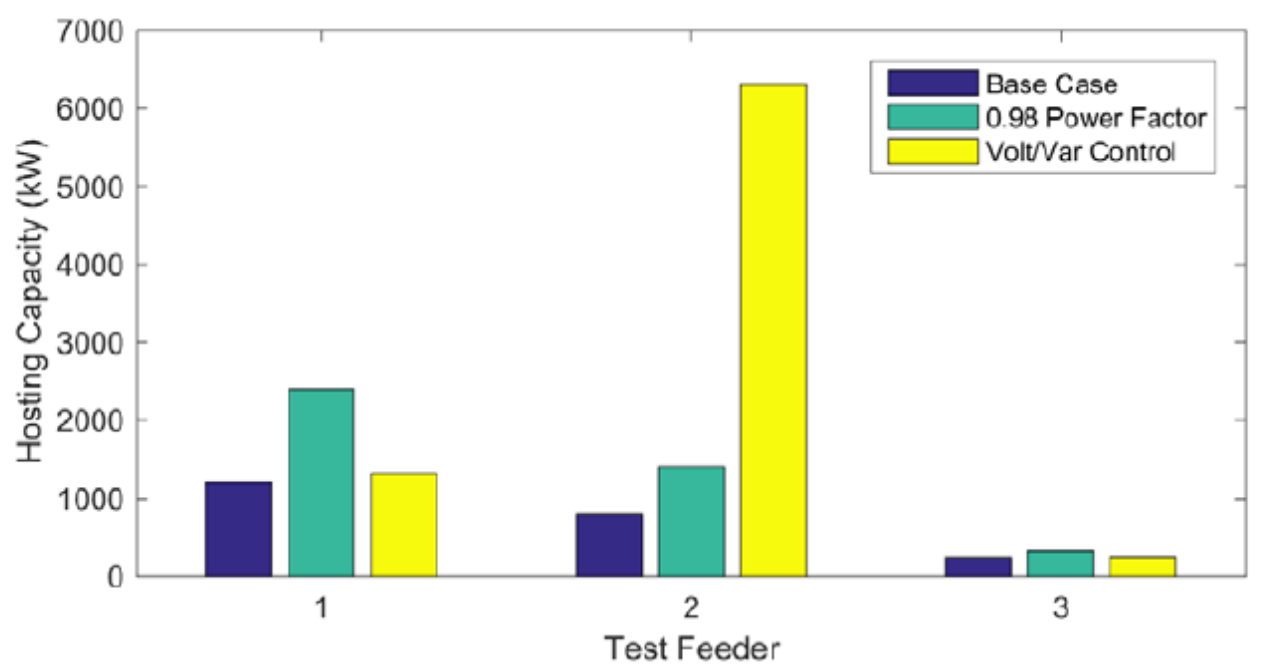

Source: Palmintier et al. (2016)

Figure 9. Results of application of voltage regulation inverters on the hosting capacity of three test feeders

The following list summarizes key decision points and stakeholders related to voltage regulation considerations:

\section{Utilization of voltage regulation capabilities:}

Utilization of the voltage regulation capabilities is at the discretion of the AEPSO, as the entity typically responsible for maintaining the distribution grid voltage. In some jurisdictions, other stakeholders, such as the AGIR or other rulemaking entity, might have some say in the use of voltage regulation capabilities through the public utility regulatory process or other means. ${ }^{18}$

\section{Determination of required DER normal operating performance category:}

From a procedural point of view, this is the responsibility of the AEPSO; however, in certain cases, the AEPSO should expect the AGIR to provide high-level direction to the AEPSO on which category is needed - for example, as a result of market or policy considerations, such as an incentivization of a specific type of DER; considerations for the long-term intended purpose and use of the DER; considerations for grid integration, such as managing characteristics of the area EPS; or considerations for the development of specific market segments.

In IEEE Std 1547-2018, Clause 5.1 is an introduction and provides an overview of voltage and reactive power capabilities and control requirements for DERs operating under normal operating conditions. Annex B (informative) presents discussion and considerations for performance category assignment.

\footnotetext{
${ }^{18}$ For more discussion on voltage regulation, see the Interstate Renewable Energy Counsel's primer on IEEE Std 1547-2018 adoption at https://irecusa.org/wp-content/uploads/2019/01/IEEE-FINAL_012919.pdf.
} 
For inverter-based DERs, Category B is recommended because it provides additional capability at little to no extra cost, and nearly all inverters are expected to have Category B capability.

\section{Determination of which voltage regulation modes will be enabled:}

As in the case of the overall assignment of normal operating performance categories, from a procedural point of view, this is the responsibility of the AEPSO; however, the AGIR could choose to provide direction to the AEPSO for a variety of reasons, as noted.

In IEEE Std 1547-2018, Clause 5.3, on voltage and reactive power control, and Clause 5.4 , on voltage and active power control, list requirements for each voltage regulation capability (voltage regulation modes). Subclauses 5.3.3 through 5.3.5 and Subclause 5.4.2 specify the default and ranges of allowable settings for the relevant electrical parameters for each voltage regulation mode.

If more fine-tuning is required beyond what the default settings provide, several steps will be needed, including potentially modeling and simulation to determine the effects of each mode on a circuit.

4. Determination of whether the voltage regulation mode settings will be adjusted locally or remotely:

This would typically be specified by the AEPSO; however, this decision might include considerations that depend on AGIR judgment or policy-for example, considerations for grid modernization; remote communications and cybersecurity; choice of communications protocol; and market structure, such as third-party service providers.

\section{Determination of target power factor if constant power factor mode is enabled:}

This is a highly localized setting, and it is specified by the AEPSO because it requires operational knowledge of reactive power demands of the local EPS and knowledge of power factor requirements at the reference point of applicability (see Note 62 in IEEE Std 1547-2018). Analysis should include calculating the effect of DERs on the area EPS primary service voltage. To determine the voltage at the local EPS, the AEPSO will apply operational knowledge of circuit configuration and type of service (e.g., whether the local EPS is serviced by a dedicated service transformer or a dedicated feeder/circuit). The AGIR might also become involved, especially if a power factor less than approximately 0.95 is used because the DER energy production could be impacted.

\section{Determination of the specified curves of volt-var, watt-var, and/or volt-watt modes,} if enabled:

This should be specified by the AEPSO, likely in coordination with the AGIR, which might receive input from other stakeholders. A detailed study including modeling of secondary circuits is needed to accurately predict the impact of a given curve on the voltage profile over time; however, the default volt-var and volt-watt curves are likely to provide some benefit.

7. If enabled, determination of autonomous reference voltage adjustability and associated time constant for autonomous adjustment of reference voltage:

This is also a highly localized setting, and it is specified by the AEPSO. 


\section{Use of dynamic voltage support:}

The voltage regulation capabilities discussed are intended to be used under normal grid conditions. Note that IEEE Std 1547-2018 allows the use of a capability called "dynamic voltage support." This concept is discussed in the standard under Subclause 6.4.2.6.2. The dynamic voltage support capability can be used to improve DER performance during transient voltage excursions that extend into low-voltage ride-through or high-voltage ride-through regions. In this mode, the DER provides rapid reactive power exchanges with the distribution system during voltage excursions, and it can help improve voltage stability during the voltage excursion. Although this is not a requirement, for DERs that have this capability, it can be used by mutual agreement with the AEPSO. Note that IEEE Std 1547-2018 does not specify this functionality in detail, and DERs are not required to be capable of it, so implementing it would require specifying the details of the functionality and confirming that DER products will be available with the desired capability. 
As AEPSOs and AGIRs adopt these new capabilities for voltage regulation and DER operators implement, certain issues will become apparent. As described in this report, determining the appropriate and beneficial modes and settings is not trivial. Instead, many factors affect how well these voltage regulation capabilities perform when applied in a specific location on an area EPS feeder, including variations in feeder topology, impedance, configuration, and loading. As DER penetration increases, so too will the necessary amount of engineering study and modeling. The most common approach to date is to select a single DER profile that works reasonably well for all DERs in a service territory rather than attempting to tune individual settings for each DER. Note also that IEEE Std 1547-2018 sets the capabilities for individual DER systems, not aggregations of multiple systems. 


\section{References}

Beaty, H. Wayne, and Donald G. Fink, eds. 2013. Standard Handbook for Electrical Engineers. 16th ed. New York: The McGraw-Hill Companies, Inc.

Blume, Steven W. 2007. Electric Power System Basics: For the Nonelectrical Professional. IEEE Press Series on Power Engineering. Hoboken, New Jersey: John Wiley \& Son.

Giraldez, Julieta I., Adarsh Nagarajan, Peter Gotseff, Venkat Krishnan, Andy Hoke, Reid Ueda, Jon Shindo, Marc Asano, and Earle Ifuku. 2017. Simulation of Hawaiian Electric Companies Feeder Operations with Advanced Inverters and Analysis of Annual Photovoltaic Energy Curtailment. Golden, CO: National Renewable Energy Laboratory. NREL/TP-5D00-68681. https://doi.org/10.2172/1373489.

Giraldez, Julieta, Andy Hoke, Peter Gotseff, Nick Wunder, Michael Blonsky, Michael Emmanuel, Aadil Latif, Earle Ifuku, Marc Asano, Thomas Aukai, and Reid. Sasaki. 2018. Advanced Inverter Voltage Controls: Simulation and Field Pilot Findings. Golden, CO: National Renewable Energy Laboratory. NREL/TP-5D00-72298.

https://www.nrel.gov/docs/fy19osti/72298.pdf.

Gonen, Turan. 2008. Electric Power Distribution System Engineering. 2nd ed. CRC Press Taylor \& Francis Group.

Hoke, Andy. 2019. "Smart Inverter Utility Experience in Hawaii." Presented at the IEEE PES General Meeting Tutorial on Smart Inverters for Distributed Generators, Atlanta, Georgia, August 4, 2019. https://www.nrel.gov/docs/fy19osti/74091.pdf.

Institute of Electrical and Electronics Engineers (IEEE). 2018. IEEE 1547-2018 - Standard for Interconnection and Interoperability of Distributed Energy Resources with Associated Electric Power Systems Interfaces. Piscataway, NJ. https://standards.ieee.org/standard/1547-2018.html.

—. 2020. IEEE Std 1547.1-2020 - Standard Conformance Test Procedures for Equipment Interconnecting Distributed Energy Resources with Electric Power Systems and Associated Interfaces. Piscataway, NJ. https://standards.ieee.org/standard/1547_1-2020.html.

Kaua'i Island Utility Cooperative. 2019. By the Numbers: KIUC 2018 Annual Report. Lihue, HI. https://website.kiuc.coop/sites/kiuc/files/documents/AnnualReport2018.pdf.

McGranaghan, Mark, Thomas Ortmeyer, David Crudele, Thomas Key, Jeff Smith, and Phil Barker. 2008. Renewable Systems Interconnection Study: Advanced Grid Planning and Operations. Albuquerque, NM: Sandia National Laboratories. SAND2008-0944 P. https://www1.eere.energy.gov/solar/pdfs/advanced_grid_planning_operations.pdf.

National Electrical Manufacturers Association (NEMA). 2016. ANSI C84.1-2016 American National Standard for Electric Power Systems and Equipment-Voltage Ratings (60 Hertz). Arlington, VA. 
Palminter, Bryan, Barry Mather, Michael Coddington, Kyri Baker, and Fei Ding. 2016. "On the Path to SunShot: Emerging Issues and Challenges in Integrating Solar with the Distribution System." Presented in May 2016, 99.

Southern California Edison (SCE). 2021. Electrical Service Requirements (ESR): Revision Summary. Rosemead, CA. https://www.sce.com/sites/default/files/customfiles/Electrical\%20Service\%20Requirements\%20(ESR).pdf.

U.S. Department of Energy. 1992. Electrical Science, Volume 3 of 4-DOE Fundamentals Handbook. DOE-HDBK-1011/3-92. Washington, D.C.

https://www.standards.doe.gov/standards-documents/1000/1011-bhdbk-1992-v3. 


\section{Appendix A. Topic Refresher-ANSI C84.1}

ANSI C84.1, the American National Standard for Electric Power Systems and EquipmentVoltage Ratings (60 Hertz), is a standard approved by the American National Standards Institute (ANSI) and published by the National Electrical Manufacturers Association (NEMA). The latest revision of the standard was published in 2016 (ANSI C84.1-2016). Originally published in 1954, the standard traces its roots to a 1942 publication by the Edison Electric Institute titled Utilization Voltage Standardization Recommendations, EEI Pub. No. J-8. (NEMA 2016).

ANSI C84.1 is a foundational document in that it establishes nominal voltage ratings and operating tolerances for electric power systems in the United States operating at $60 \mathrm{~Hz}$ between $100 \mathrm{~V}$ and $1,200 \mathrm{kV}$. Requirements in ANSI C84.1 are applied to other standards - including the Institute of Electrical and Electronics Engineers (IEEE) 1547 Standard for Interconnection and Interoperability of Distributed Energy Resources with Associated Electric Power Systems Interfaces (IEEE Std 1547) — and are used to define voltage ratings for electric utility equipment as well as customer end-use devices (NEMA 2016).

The standard dictates the voltage ranges at which area electric power system operators (AEPSOs) must maintain typical distribution systems and dictates the operating range of voltages that must be designed into equipment connecting to the distribution system, including all end-user loads and distributed energy resources. Key terms defined in ANSI C84.1 are used extensively in utility practice and are referenced by IEEE Std 1547-2018.

Nominal system voltage is defined as "the voltage by which a portion of the system is designated, and to which certain operating characteristics of the system are related" (NEMA 2016). For this discussion, nominal system voltage can be understood to be the general voltage rating of the equipment connecting to the area EPS.

Service voltage is defined as "the voltage at the point where the electrical system of the supplier and the electrical system of the user are connected" (NEMA 2016). For this discussion, the service voltage can be understood to mean the sustained voltage delivered by the AEPSO at the point of common coupling.

Under normal operating conditions, the AEPSO must maintain the service voltage within the minimum and maximum given for Range A. Voltage may only stray outside Range A infrequently, and then only up to the limits within Range B.

Service voltage Range B was developed to address the fact that consumer equipment and electric supply systems are designed and operated in a variety of ways; and in some cases, voltages may sometimes stray outside Range A for a limited period of time. It is expected that if this occurs, action will be taken to restore the voltage back to within Range A.

Utilization voltage is defined as "the voltage at the line terminals of utilization equipment" (NEMA 2016). Consumer systems must be designed to give satisfactory performance throughout utilization voltage Range A and must be designed and operated so that if the electric supply system voltages are sustained within service voltage Range A, most utilization voltages will be within utilization voltage Range A. 
Utilization voltage Range B was developed to address the fact that consumer equipment and electric supply systems are designed and operated in a variety of ways, and voltages may sometimes stray outside Range A for a limited time. It is expected that if this occurs, action will be taken to restore the voltage back to within Range A.

Table A-1 lists the voltage ranges and limits for residential single-phase systems specified in ANSI C84.1.

Table A-1. ANSI Voltage Ranges and Limits for Residential Single-Phase Systems

\begin{tabular}{|c|c|c|c|c|c|}
\hline & $\begin{array}{c}\text { Nominal } \\
\text { System Voltage }\end{array}$ & \multicolumn{2}{|c|}{ Service Voltage } & \multicolumn{2}{c|}{ Utilization Voltage } \\
\hline & $\mathbf{V},($ p.u.) & $\begin{array}{c}\text { Minimum } \\
\text { V, p.u.) }\end{array}$ & $\begin{array}{c}\text { Maximum } \\
\text { V, (p.u.) }\end{array}$ & $\begin{array}{c}\text { Minimum } \\
\text { V, (p.u.) }\end{array}$ & $\begin{array}{c}\text { Maximum } \\
\text { V, (p.u.) }\end{array}$ \\
\hline $\begin{array}{l}\text { Voltage } \\
\text { Range A }\end{array}$ & $120,(1.00)$ & $114,(0.95)$ & $126,(1.05)$ & $108,(0.90)$ & $125,(\approx 1.04)$ \\
\hline $\begin{array}{l}\text { Voltage } \\
\text { Range B }\end{array}$ & $120,(1.00)$ & $110,(\approx 0.92)$ & $127,(\approx 1.06)$ & $104,(\approx 0.87)$ & $127,(\approx 1.06)$ \\
\hline
\end{tabular}

See ANSI C84.1-2016 for a more complete discussion of requirements (NEMA 2016). 


\section{Appendix B. Advanced Voltage Regulation-A Hawaii Case Study}

\section{Background}

Hawaii has a unique status in terms of solar energy integration into the electric grid. In the United States, Hawaii has the highest distributed photovoltaic (PV) capacity (more than 50\% of peak load). One reasons for this high PV penetration is the historical PV incentives in Hawaii. The state is actively working to achieve its goal of $100 \%$ renewables by 2045 . Already by 2018 , peak island-wide PV penetration was in the range of $50 \%-80 \%{ }^{19}$ The large share of PV is creating power quality issues, such as occasional steady-state overvoltage issues, in the distribution network. To deal with adverse effects of high PV penetration and mitigate these issues, Hawaiian Electric Companies is investigating the use of advanced grid support functions of smart inverters. Based on the results of these investigations, Hawaii became the first state to mandate advanced grid support functions from smart inverters, even before these functions were finalized in standards.

One study included the National Renewable Energy Laboratory in partnership with Hawaiian Electric Companies and the Smart Inverter Technical Working Group Hawaii. Under this project, the team conducted research on a subset of Hawaiian distribution feeders with the aim to understand the operational and power curtailment impacts when different voltage regulation functions are enabled (Giraldez et al. 2017).

\section{Research Methodology and Result}

The research team identified two feeders from Oahu Island for quasi-time-series simulation analysis to address the operational issues and PV curtailment with varying PV penetration levels. The models of the feeders for time-series simulation were constructed and validated using operational data. Once the feeder models were developed and validated, different scenarios were simulated and analyzed for combinations of voltage regulation strategies. Mainly, three voltage regulation strategies were considered: 0.95 constant power factor (p.f.), volt-volt ampere reactive, and volt-watt. Key findings of the studies are summarized as follows:

- Volt-var was found to result in fewer voltage violations, fewer tap-changer operations, reduced losses, and less PV curtailment than a fixed PF of 0.95.

- PV energy curtailment resulting from use of volt-var and volt-watt voltage regulation modes was near zero in almost all cases, with a few outliers.

- Volt-var was recommended to be used in combination with volt-watt to protect the system from overvoltages (particularly in dense suburban secondary circuits).

\footnotetext{
${ }^{19}$ Hawaii is also home to the Kaua' $i$ Island Utility Cooperative, which serves approximately 37,000 accounts, with $77 \%$ of those being residential customers. The cooperative's generation capacity is close to $210 \mathrm{MW}$, with $95 \mathrm{MW}$ coming from PV energy systems (64 MW utility-scale and $31 \mathrm{MW}$ distributed rooftop systems). As of 2019, Kaua'i Island Utility Cooperative's overall 119-MW renewable portfolio also included approximately 7 MW of biomass and approximately $17 \mathrm{MW}$ of hydropower. Two utility-scale solar fields include a combined 152 hours of battery energy storage, which allows $40 \%$ of Kaua'i evening peak load to be met by dispatchable solar energy (Kaua' $i$ Island Utility Cooperative 2019).
} 
- Volt-var and volt-watt are most beneficial if deployed system-wide.

\section{Implementation Experience of Voltage Regulation Functions}

The simulation study findings were validated and expanded through a pilot study (Giraldez et al. 2018), through which the National Renewable Energy Laboratory and Hawaiian Electric Companies installed monitoring sensors and communications to approximately $30 \mathrm{PV}$ locations expected to have high voltage. The pilot project revealed that PV energy curtailment resulting from volt-var and volt-watt was zero or near zero at the locations (at least for the volt-var curve used in Hawaii). In one of the two locations, , where curtailment was found to be more than $1 \%$, a conventional (wire) solution proved to be effective. Based on these studies, Hawaiian Electric was the first utility to require activation of volt-var for all new distributed energy resources. Activation of volt-var helped the utility to reduce overvoltage and improve rooftop PV system hosting capacity (Hoke 2019). 